\title{
Modulatory effects of black $v$. green tea aqueous extract on hyperglycaemia, hyperlipidaemia and liver dysfunction in diabetic and obese rat models
}

\author{
Gamal Ramadan*, Nadia M. El-Beih and Eman A. Abd El-Ghffar \\ Zoology Department, Faculty of Science, Ain Shams University, Abbasseya 11566, Cairo, Egypt \\ (Received 9 April 2009 - Revised 14 August 2009 - Accepted 17 August 2009 - First published online 13 October 2009)
}

Cardiovascular complications are a major cause of morbidity and mortality in patients with diabetes, obesity and the metabolic syndrome. Recently, there has been an increasing interest in tea as a protective agent against CVD. Here, we compared the modulatory effects of two different doses $(50$ and $100 \mathrm{mg} / \mathrm{kg}$ body weight given orally for 28 consecutive days) of black tea aqueous extract (BTE, rich in theaflavins and thearubigins) and green tea aqueous extract (GTE, rich in catechins) on experimentally induced hyperglycaemia, hyperlipidaemia and liver dysfunction by alloxan (which destroys pancreatic $\beta$-cells and induces type 1 diabetes) and a cholesterol-rich diet (which induces obesity and type 2 diabetes) in male Wistar albino rats. Both tea extracts significantly alleviated most signs of the metabolic syndrome including hyperglycaemia (resulting from type 1 and 2 diabetes), dyslipidaemia and impairment of liver functions induced by alloxan or the cholesterol-rich diet in the animals. Also, the tea extracts significantly modulated both the severe decrease and increase in body weight induced by alloxan and the high-cholesterol diet, respectively. The modulatory effects obtained here were partial or complete, but significant and dose dependent, and slightly more in GTE in most cases. No harmful effects were detected for tea consumption on all parameters measured, except that the high dose of both tea extracts significantly decreased the spleen weight:body weight ratio and induced lymphopenia. The present study supports the hypothesis that both black and green teas may have beneficial effects against the risks of the metabolic syndrome and CVD as shown in rat models of human obesity and diabetes.

Albino rats: Alloxan: Hypercholesterolaemia: Hyperglycaemia: Liver dysfunction: Tea

Diabetes, a disorder of metabolism, is increasingly affecting more and more individuals in the world and the number of individuals suffering from diabetes worldwide is predicted to reach 325 million by the year $2025^{(1)}$. There are two forms of diabetes mellitus: type 1 and 2 . In type 1 diabetes or insulin-dependent diabetes mellitus the pancreatic $\beta$-cells are progressively destroyed and secrete little or no insulin. Type 2 diabetes or non-insulin-dependent diabetes mellitus is a heterogeneous disorder of insulin resistance and pancreatic $\beta$-cell dysfunction ${ }^{(2,3)}$. About $80 \%$ of diabetic morbidity and mortality is caused by cardiomyopathy that is mainly due to diabetic dyslipidaemia ${ }^{(3)}$.

Obesity, excess body weight, is a representative lifestylerelated disorder caused by an excessively fat-rich dietary intake associated with a lack of physical exercise ${ }^{(4)}$. Obesity has increased at an alarming rate in recent years and is now a worldwide health problem, since it is a major risk factor for CVD, type 2 diabetes, impairment of liver functions and even cancer, for which the social costs are incalculable ${ }^{(5-7)}$.

Hyperglycaemia in addition to alterations in plasma lipids and lipoproteins in streptozotocin-diabetic rats ${ }^{(8)}$, mice fed a high-fat $\operatorname{diet}^{(9)}$ and obese humans ${ }^{(10)}$ affect cardiovascular circulation and cardiac output and increase the risk of atherosclerosis and CHD. Now there is a solid body of evidence which links the consumption of tea to a reduced risk of CVD by improving glucose and lipid metabolism.

Tea, from the plant Camellia sinensis, is one of the most popular beverages consumed worldwide. Tea is rich in antioxidant polyphenolic flavonoids (catechins, flavonols, theaflavins and thearubigins) that possess various pharmacological effects such as anti-hypertensive, anti-arteriosclerotic, hypoglycaemic and hypocholesterolaemic activity ${ }^{(8,11-14)}$. Green tea (unfermented tea) is favoured in Asian countries especially Japan and China, whereas black tea (fully fermented tea) is favoured in the Western world ${ }^{(2)}$. The processing methods of tea yield preparations with differing chemical compositions and perhaps differing efficacies. During the manufacture of black tea, polyphenol oxidase in fresh tea leaves oxidises catechins (tea tannins) into quinones, which condense to form theaflavins and thearubigins ${ }^{(2,15,16)}$. This fermentation process is inactivated by steam or pan firing treatment of freshly harvested tea leaves to produce green tea ${ }^{(2,17)}$. The catechins (epicatechin, epicatechin gallate, epigallocatechin and epigallocatechin gallate) and flavonols (kaempferol, quercetin and myricetin glycosides) of green tea represent $80-90 \%$ and $<10 \%$ of total flavonoids, respectively. On the other

Abbreviations: A:G, albumin:globulin; ALP, alkaline phosphatase; AMPK, AMP-activated protein kinase; BTE, black tea aqueous extract; GTE, green tea aqueous extract.

* Corresponding author: Dr Gamal Ramadan, fax +20226842123, email gamal_ramadan@hotmail.com 
hand, the catechin content of black tea is only $20-30 \%$, whilst the theaflavins and thearubigins represent about 10 and $50-60 \%$ of total flavonoids, respectively ${ }^{(15,16)}$.

Despite the considerable difference in the chemical composition of both tea extracts, studies comparing the glucose- and lipid-lowering activity of black and green tea in rat models of human obesity and diabetes are limited. Therefore, the main purpose of the present study was to compare the modulatory effects of black tea extracts (rich in theaflavins and thearubigins) with green tea extracts (rich in catechins) on experimentally induced hyperglycaemia, hyperlipidaemia and liver dysfunction by alloxan (which destroys pancreatic $\beta$-cells) and a cholesterol-rich diet (which induces obesity and insulin resistance) in male Wistar albino rats. Furthermore, the present study investigated any deleterious effects caused by the consumption of black and green tea extracts.

\section{Materials and methods}

\section{Chemicals and tea preparations}

Alloxan monohydrate $\left(\mathrm{C}_{4} \mathrm{H}_{2} \mathrm{~N}_{2} \mathrm{O}_{4} \cdot \mathrm{H}_{2} \mathrm{O} ;\right.$ molecular weight $160 \cdot 08 \mathrm{Da})$ and cholesterol $\left(\mathrm{C}_{27} \mathrm{H}_{46} \mathrm{O}\right.$, molecular weight 386.66 Da) were purchased from Sigma-Aldrich (St Louis, MO, USA) and WinLab (Market Harborough, Leics, UK), respectively. Black and green teas (R. Twining \& Co. Ltd, London, UK) were purchased from a public market in Cairo, Egypt. Black tea aqueous extract (BTE) and green tea aqueous extract (GTE) were prepared by dissolving amounts equivalent to 50 and $100 \mathrm{mg}$ tea leaf powder per $\mathrm{kg}$ body weight in glassware containing $0.5 \mathrm{ml}$ boiling distilled water (equivalent to 1.5 and 3 cups of tea, respectively), then covered and let stand for $10 \mathrm{~min}$ at room temperature. After that the extracts were filtered and given fresh to the animals ${ }^{(18)}$.

\section{Experimental animals and treatment schedule}

Adult male Wistar albino rats (Rattus norvegicus), weighing about $120 \mathrm{~g}$, were obtained from the National Research Centre in Giza, Egypt. Animals were housed in suitable cages and acclimatised to laboratory conditions for a period of 1 week before the commencement of the experiments. Rats were fed standard rodent food pellets (AgriculturalIndustrial Integration Company, Giza, Egypt) and doubledistilled water. The standard rodent food pellets contain wheat-bran, dried clover, maize, bean-hay, methionine, molasses, salt, in addition to mineral and vitamin mixes. The amount of crude proteins, fats and fibres in the food pellets are $12,2.4$ and $14 \%$, respectively. The energy content of the standard diet is $920.48 \mathrm{~kJ} / 100 \mathrm{~g}$. All animals were humanely treated in accordance with the WHO guideline for animal care and the study design was approved by the Ain Shams University Research Ethics Committee.

Experimental animals were divided randomly into fifteen groups of seven rats each: five healthy groups, five diabetic groups and five obese groups. In healthy groups, animals were treated by oral administration and daily with 50 or $100 \mathrm{mg} / \mathrm{kg}$ body weight (low or high dose, respectively) of either BTE or GTE for 4 weeks. The control animals received orally and daily $0.5 \mathrm{ml}$ distilled water, as vehicle, and were housed in cages for 4 weeks under the same conditions as the other groups. In diabetic groups, animals were injected subcutaneously by alloxan $(120 \mathrm{mg} / \mathrm{kg}$ body weight $)$ for the first $3 \mathrm{~d}$ only to induce hyperglycaemia ${ }^{(19)}$ and given orally and daily the low or high dose of either BTE or GTE for 4 weeks. Alloxan-only-treated animals received orally and daily $0.5 \mathrm{ml}$ distilled water and were housed in cages for 4 weeks under the same conditions as the other groups. In obese groups, animals were fed a cholesterol-rich diet (standard rodent food pellets plus $2 \%$ cholesterol, w/w) to induce hyperlipidaemia ${ }^{(20,21)}$ and given orally and daily the low or high dose of either BTE or GTE for 4 weeks. Cholesterol-only-treated animals received orally and daily $0.5 \mathrm{ml}$ distilled water and were housed in cages for 4 weeks under the same conditions as the other groups.

\section{Blood and tissue sampling}

The rats were subjected to light diethyl ether anaesthesia before killing. The blood was collected into clean test-tubes with or without EDTA. A portion of blood with EDTA was used to determine the total and differential leucocyte counts. Another blood portion without EDTA was left to coagulate at room temperature and the clotting time was recorded using a stopwatch. Then, blood was centrifuged in a cooling centrifuge (IEC centra-4R; International Equipment Co., Needham Heights, MA, USA) for $30 \mathrm{~min}$ at $3000 \mathrm{rpm}$ and $4^{\circ} \mathrm{C}$ to separate the clot. The serum was separated at once by a long Pasteur pipette, divided into samples and preserved at $-70^{\circ} \mathrm{C}$ for further analysis. Immediately after killing the animals, the liver and spleen were separated out of the body, cleaned and weighed.

\section{Measurements}

Food intake (on a per-group basis) was measured weekly. Body-weight gain or loss was calculated by the following equation: body-weight gain or loss = body weight at the end of the experiment - body weight at the beginning of the experiment. All biochemical analyses were manually done using commercial kits. Serum glucose, total protein, albumin, total lipids, TAG, phospholipids, total cholesterol, HDLcholesterol and bilirubin (total and direct) concentrations were determined either enzymically or colorimetrically using Diamond Diagnostics (DP International, Cairo, Egypt) and Sentinel CH (Milan, Italy) kits ${ }^{(22-31)}$. Serum alanine and aspartate aminotransferases and alkaline phosphatase (ALP) activities were estimated either colorimetrically or kinetically using BioMérieux SA (Marcy-l'Etoile, France) and Biocon Diagnostik (Vöhl-Marienhagen, Germany) kits ${ }^{(32,33)}$.

Serum total globulins and indirect bilirubin concentrations were calculated according to the following equations: total globulins $=$ serum total protein - albumin; indirect bilirubin $=$ total bilirubin - direct bilirubin. LDL-cholesterol concentration was calculated according to the equation of Friedewald et $a l .{ }^{(34)}$ : LDL-cholesterol $=$ total cholesterol $-($ TAG/5) HDL-cholesterol. Atherogenic indexes were calculated as follows: atherogenic index $(1)=$ total cholesterol:HDL-cholesterol ratio; atherogenic index (2) = LDL-cholesterol:HDLcholesterol ratio.

Total and differential leucocyte counts were measured by Coulter (Hemat 8 analyser; SEAC, Freiburg, Germany) 
using $0.5 \mathrm{ml}$ fresh anti-coagulated blood. The percentage of change of any parameter $=((\mathrm{T}-\mathrm{C}) / \mathrm{C}) \times 100$, where $(\mathrm{T})=$ the mean value of the parameter in the treated group and (C) $=$ the mean value of the parameter in the control group.

\section{Statistics}

Data are presented as mean values with their standard errors. Statistical analysis was performed with one-way ANOVA and the differences among groups were determined by Bonferroni's multiple comparison test ${ }^{(35)}$ using GraphPad Prism version 4.03 for Windows (GraphPad Software Inc., San Diego, CA, USA). Statistically significant variations were compared as follows: (a) all groups $v$. the control group; (b) alloxan plus tea extracts-treated groups $v$. the alloxan-onlytreated group; (c) cholesterol plus tea extracts-treated groups $v$. the cholesterol-only-treated group. $P$ values of $<0.05$ and $<0.01$ were considered significant and highly significant, respectively.

\section{Results}

\section{Modulatory effects of black tea aqueous extract compared} with green tea aqueous extract on diabetic rats

The present study showed that treatment of rats with alloxan alone did not significantly alter $(P>0 \cdot 05, t=2 \cdot 597$, difference between means $=-0.0024,95 \%$ CI $-0.0053,0.0006)$ the liver weight:body weight ratio, but induced a highly significant increase $(P<0 \cdot 01)$ in clotting time, serum glucose, total lipid, TAG, phospholipid and bilirubin (total and indirect) levels, total cholesterol:HDL-cholesterol and LDL-cholesterol:HDL-cholesterol ratios, and serum aminotransferase and
ALP activities compared with the control animals (Tables $1-3)$. On the other hand, it induced a highly significant decrease $(P<0 \cdot 01)$ in body weight, serum total protein and direct bilirubin levels, and albumin:globulins (A:G) ratio compared with the control animals (Tables 1 and 3 ).

Both tea extracts significantly alleviated $(P<0.05-$ $P<0.01$ ) the severe decrease in body weight (Table 1) and the increase in serum glucose, total lipid, TAG and phospholipid levels (Tables 1 and 2), atherogenic index values (Table 2), and serum aminotransferase and ALP activities (Table 3) induced by alloxan. These modulatory effects of tea extracts were dose dependent and slightly more in GTE groups compared with BTE groups in most cases. Serum TAG levels became comparable with that of the control group $(P>0 \cdot 05, t=3 \cdot 170$, difference between means $=-11.44,95 \% \mathrm{CI}-23 \cdot 28,0.40)$ in the group treated with alloxan plus the high dose of GTE only. There were no significant modulatory effects of both tea extracts on clotting time, serum total protein and bilirubin (total, direct and indirect) levels, and $\mathrm{A}: \mathrm{G}$ ratio in alloxan plus tea extractstreated groups compared with the alloxan-only-treated group. Food intake was not significantly changed $(P>0.05)$ in alloxan with or without tea extracts-treated groups compared with the control group (Fig. 1).

The percentages of changes of all parameters measured in the alloxan-only-treated group, groups treated with alloxan plus either the low or high dose of BTE, and groups treated with alloxan plus either the low or high dose of GTE were 124.9 (SEM 54.3), 81.2 (SEM 43.5), 50.9 (SEM 27.5), 79.9 (SEM 47.1) and 40.0 (SEM 22.2), respectively, compared with the control group. All of these results revealed that the most modulatory effects on diabetic rats were induced by the high dose of BTE and GTE.

Table 1. The modulatory effects of tea aqueous extracts on body and liver weight, clotting time, and serum levels of glucose and proteins in healthy, diabetic, and obese rat models

(Mean values with their standard errors)

\begin{tabular}{|c|c|c|c|c|c|c|c|c|c|c|c|c|}
\hline \multirow[b]{2}{*}{ Group } & \multicolumn{2}{|c|}{$\begin{array}{l}\text { Body-weight gain } \\
\text { or loss }(\mathrm{g})\end{array}$} & \multicolumn{2}{|c|}{$\begin{array}{l}\text { Liver:body } \\
\text { weight ratio }\end{array}$} & \multicolumn{2}{|c|}{$\begin{array}{l}\text { Clotting } \\
\text { time (s) }\end{array}$} & \multicolumn{2}{|c|}{ Glucose (mg/l) } & \multicolumn{2}{|c|}{$\begin{array}{c}\text { Total } \\
\text { protein }(g / l)\end{array}$} & \multicolumn{2}{|c|}{ A:G ratio } \\
\hline & Mean & SEM & Mean & SEM & Mean & SEM & Mean & SEM & Mean & SEM & Mean & SEM \\
\hline Control & $45 \cdot 9$ & $1 \cdot 1$ & 0.0268 & 0.0005 & $56 \cdot 0$ & 1.6 & 874 & 56 & $46 \cdot 2$ & $2 \cdot 4$ & 1.03 & 0.05 \\
\hline BTE 50 & 47.9 & 1.5 & 0.0262 & 0.0004 & $57 \cdot 0$ & 0.9 & 791 & 13 & $45 \cdot 8$ & $2 \cdot 3$ & 1.03 & 0.06 \\
\hline BTE 100 & 41.7 & $1 \cdot 1$ & 0.0248 & 0.0002 & $56 \cdot 0$ & 1.9 & $679^{\star *}$ & 8 & $46 \cdot 6$ & $2 \cdot 0$ & 1.07 & 0.07 \\
\hline GTE 50 & $45 \cdot 3$ & 1.6 & 0.0267 & 0.0002 & 57.3 & 0.8 & 774 & 11 & $46 \cdot 6$ & 1.9 & 1.03 & 0.05 \\
\hline GTE 100 & $35 \cdot 0^{\star \star}$ & 1.9 & 0.0252 & 0.0004 & $57 \cdot 7$ & 1.3 & $663^{\star \star}$ & 12 & $46 \cdot 0$ & 1.9 & 0.96 & 0.05 \\
\hline Alloxan & $-15 \cdot 4^{\star \star}$ & 0.8 & 0.0292 & 0.0004 & $81 \cdot 1^{\star *}$ & 5.9 & $3020^{\star \star}$ & 39 & $35 \cdot 3^{\star *}$ & 2.5 & $0.64^{\star *}$ & 0.09 \\
\hline Alloxan + BTE 50 & $8 \cdot 9^{* *}+\dagger$ & 0.8 & 0.0290 & 0.0002 & $77 \cdot 6^{\star \star}$ & 7.5 & $1496^{\star \star}+\dagger$ & 16 & $33 \cdot 8^{\star \star}$ & 1.8 & $0.40^{\star \star}$ & 0.03 \\
\hline Alloxan + BTE 100 & $18 \cdot 1^{* *} \dagger \dagger$ & 2.5 & 0.0290 & 0.0004 & $79 \cdot 0^{\star *}$ & $7 \cdot 1$ & $1330^{\star *}+\dagger$ & 20 & $34 \cdot 5^{\star *}$ & $1 \cdot 7$ & 0.86 & 0.07 \\
\hline Alloxan + GTE 50 & $16 \cdot 7^{\star \star}+\dagger$ & $2 \cdot 3$ & 0.0281 & 0.0007 & 73.7 & $5 \cdot 0$ & $1413^{\star *} \dagger \dagger$ & 16 & $33 \cdot 7^{\star \star}$ & 1.3 & $0.49^{\star \star}$ & 0.03 \\
\hline Alloxan + GTE 100 & $36 \cdot 1^{*}+\dagger$ & $3 \cdot 2$ & 0.0274 & 0.0006 & $76 \cdot 7^{\star}$ & $5 \cdot 6$ & $1271^{\star *} \dagger \dagger$ & 13 & $34 \cdot 8^{\star \star}$ & $2 \cdot 0$ & $0.43^{\star \star}$ & 0.06 \\
\hline Cholesterol & $97 \cdot 7^{\star \star}$ & 1.5 & $0.0427^{\star \star}$ & 0.0009 & $71 \cdot 1$ & 0.9 & $1504^{\star *}$ & 20 & 37.9 & 1.9 & $0.73^{\star \star}$ & 0.04 \\
\hline Cholesterol + BTE 50 & $76 \cdot 9^{\star \star}$ & 1.5 & $0.0400^{\star \star}$ & 0.0007 & $69 \cdot 3$ & $2 \cdot 5$ & $1217^{\star \star} \neq \ddagger$ & 13 & 37.6 & 1.3 & $0.76^{\star}$ & 0.07 \\
\hline Cholesterol + BTE 100 & $55 \cdot 6^{\star} \neq \ddagger$ & $3 \cdot 6$ & $0.0335^{\star \star \star} \ddagger \ddagger$ & 0.0012 & $67 \cdot 0$ & $2 \cdot 0$ & $1068^{\star *}$ 㧊 & 38 & 37.7 & $1 \cdot 6$ & 0.84 & 0.05 \\
\hline Cholesterol + GTE 50 & $70 \cdot 1^{\star \star \ddagger}$ & 1.2 & $0.0349^{\star \star} \ddagger \ddagger$ & 0.0011 & 69.4 & $2 \cdot 8$ & $1203^{\star *} \ddagger \ddagger$ & 26 & $37 \cdot 7$ & 1.3 & $0.53^{\star *}$ & 0.04 \\
\hline Cholesterol + GTE 100 & $50 \cdot 3 \neq \ddagger$ & 1.7 & $0.0330^{\star *} \ddagger \ddagger$ & 0.0006 & $67 \cdot 3$ & $2 \cdot 1$ & $1034^{\star \star} \neq \ddagger$ & 27 & 37.8 & 1.9 & $0.59^{\star \star}$ & 0.03 \\
\hline
\end{tabular}

A:G ratio, albumin:globulin ratio; BTE 50 , black tea aqueous extract $(50 \mathrm{mg} / \mathrm{kg}$ body weight); BTE 100 , black tea aqueous extract (100 mg/kg body weight); GTE 50 , green tea aqueous extract (50 mg/kg body weight); GTE 100 , green tea aqueous extract ( $100 \mathrm{mg} / \mathrm{kg}$ body weight).

Mean value was significantly different from that of the control group: ${ }^{*} P<0.05,{ }^{\star *} P<0.01$.

Mean value was significantly different from that of the alloxan-only-treated group: $\dagger P<0.05, \dagger \dagger P<0.01$.

Mean value was significantly different from that of the cholesterol-only-treated group: $\ddagger P<0.05, \ddagger \ddagger P<0.01$. 
Table 2. The modulatory effects of tea aqueous extracts on serum lipid profile and atherogenic indexes in healthy, diabetic, and obese rat models (Mean values with their standard errors)

\begin{tabular}{|c|c|c|c|c|c|c|c|c|c|c|}
\hline & \multicolumn{2}{|c|}{ Total lipids (mg/l) } & \multicolumn{2}{|c|}{ TAG (mg/l) } & \multicolumn{2}{|c|}{$\begin{array}{l}\text { Phospholipids } \\
\text { (mg/l) }\end{array}$} & \multicolumn{2}{|c|}{$\begin{array}{l}\text { Atherogenic } \\
\text { index (1) }\end{array}$} & \multicolumn{2}{|c|}{$\begin{array}{l}\text { Atherogenic } \\
\text { index (2) }\end{array}$} \\
\hline & Mean & SEM & Mean & SEM & Mean & SEM & Mean & SEM & Mean & SEM \\
\hline Control & 4679 & 167 & 527 & 6 & 1364 & 14 & 1.39 & 0.02 & 0.14 & 0.01 \\
\hline BTE 50 & 4551 & 186 & 440 & 37 & 1324 & 7 & 1.33 & 0.04 & 0.11 & 0.02 \\
\hline BTE 100 & $3723^{\star}$ & 205 & $318^{\star *}$ & 9 & 1304 & 7 & 1.23 & 0.02 & 0.06 & 0.01 \\
\hline GTE 50 & 4260 & 117 & 438 & 29 & 1320 & 12 & 1.32 & 0.06 & $0 \cdot 10$ & 0.03 \\
\hline GTE 100 & $3464^{\star *}$ & 226 & $292^{\star \star}$ & 15 & 1301 & 9 & $1 \cdot 22$ & 0.02 & 0.06 & 0.01 \\
\hline Alloxan & $7009^{\star \star}$ & 267 & $1129^{\star *}$ & 27 & $1731^{* *}$ & 15 & $3.34^{\star *}$ & 0.15 & $1.44^{\star *}$ & 0.12 \\
\hline Alloxan + BTE 50 & $6401^{\star \star}$ & 228 & $925^{\star \star} \dagger \dagger$ & 18 & $1629^{\star \star} \dagger$ & 27 & $2 \cdot 88^{\star \star}$ & 0.13 & $1 \cdot 19^{\star \star}$ & $0 \cdot 10$ \\
\hline Alloxan + BTE 100 & $5927^{\star \star} \dagger$ & 104 & $660^{*}+\dagger$ & 42 & $1491^{* *}+\dagger$ & 18 & $2 \cdot 15^{\star \star} † \dagger$ & 0.15 & $0.75^{\star \star} † \dagger$ & 0.12 \\
\hline Alloxan + GTE 50 & $6189^{\star *}$ & 214 & $764^{\star \star} \dagger \dagger$ & 17 & $1582^{* \star}+\dagger$ & 30 & $2 \cdot 89^{\star \star}$ & 0.19 & $1 \cdot 31^{\star \star}$ & 0.16 \\
\hline Alloxan + GTE 100 & $5754^{*}+\dagger$ & 281 & 642†† & 23 & $1487^{\star \star} \dagger \dagger$ & 14 & $2 \cdot 00^{*} \dagger \dagger$ & 0.14 & $0.63^{*} \dagger \dagger$ & 0.11 \\
\hline Cholesterol & $8051^{\star \star}$ & 321 & $1088^{\star *}$ & 23 & $2354^{\star \star}$ & 19 & $4 \cdot 25^{\star \star}$ & 0.17 & $2 \cdot 58^{\star \star}$ & 0.14 \\
\hline Cholesterol + BTE 50 & $6169^{\star \star} \ddagger \ddagger$ & 171 & 930 **㧊 & 32 & $1587^{\star \star} \neq \ddagger$ & 19 & $2 \cdot 89^{\star \star} \neq \ddagger$ & 0.11 & $1 \cdot 25^{\star \star} \neq \ddagger$ & $0 \cdot 10$ \\
\hline Cholesterol + BTE 100 & $5867^{\star \star} \neq \ddagger$ & 180 & $656^{\star} \neq \ddagger$ & 34 & 1478 **㧊 & 17 & $2 \cdot 23^{\star \star} \ddagger \ddagger$ & 0.17 & $0.82^{\star *} \ddagger \ddagger$ & 0.15 \\
\hline Cholesterol + GTE 50 & $5939^{\star *} \ddagger \ddagger$ & 156 & $853^{\star \star \star} \ddagger \ddagger$ & 22 & $1595^{\star \star} \ddagger \ddagger$ & 41 & $2 \cdot 88^{\star \star} \neq \ddagger$ & 0.07 & $1 \cdot 28^{\star \star} \neq \ddagger$ & 0.05 \\
\hline Cholesterol + GTE 100 & 5519ł‡ & 126 & 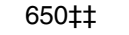 & 21 & $1466^{\star} \neq \ddagger$ & 14 & $2 \cdot 18^{\star \star} \neq \ddagger$ & 0.07 & $0 \cdot 76^{\star \star} \neq \ddagger$ & 0.05 \\
\hline
\end{tabular}

Atherogenic index (1), total cholesterol:HDL-cholesterol ratio; atherogenic index (2), LDL-cholesterol:HDL-cholesterol ratio; BTE 50, black tea aqueous extract (50 mg/kg body weight); BTE 100 , black tea aqueous extract ( $100 \mathrm{mg} / \mathrm{kg}$ body weight); GTE 50 , green tea aqueous extract (50 mg/kg body weight); GTE 100 , green tea aqueous extract $(100 \mathrm{mg} / \mathrm{kg}$ body weight).

Mean value was significantly different from that of the control group: * $P<0.05,{ }^{\star \star} P<0.01$

Mean value was significantly different from that of the alloxan-only-treated group: $\dagger P<0.05, \dagger \dagger P<0.01$.

Mean value was significantly different from that of the cholesterol-only-treated group: $\ddagger \ddagger P<0.01$.

Modulatory effects of black tea aqueous extract compared with green tea aqueous extract on obese rats

The present study showed that feeding rats a cholesterol-rich diet did not significantly alter $(P>0.05)$ the clotting time and serum total protein level (Table 1), but induced a significant increase $(P<0.05-P<0.01)$ in body weight, liver weight: body weight ratio, serum glucose, total lipid, TAG, phospholipid and bilirubin (total and indirect) levels, total cholesterol:HDL-cholesterol and LDL-cholesterol:HDL-cholesterol ratios, and serum aminotransferase and ALP activities compared with the control animals (Tables 1-3). On the other hand, it induced a highly significant decrease in A:G

Table 3. The modulatory effects of tea aqueous extracts on serum aminotransferases and alkaline phosphatase activities and bilirubin level in healthy, diabetic, and obese rat models

(Mean values with their standard errors)

\begin{tabular}{|c|c|c|c|c|c|c|c|c|c|c|c|c|}
\hline & & & & & & & \multicolumn{6}{|c|}{ Bilirubin (mg/l) } \\
\hline & \multicolumn{2}{|c|}{$\begin{array}{l}\text { ALAT activity } \\
\text { (IU/I) }\end{array}$} & \multicolumn{2}{|c|}{$\begin{array}{l}\text { ASAT activity } \\
\text { (IU/I) }\end{array}$} & \multicolumn{2}{|c|}{$\begin{array}{l}\text { ALP activity } \\
\text { (IU/I) }\end{array}$} & \multicolumn{2}{|c|}{ Total } & \multicolumn{2}{|c|}{ Direct } & \multicolumn{2}{|c|}{ Indirect } \\
\hline & Mean & SEM & Mean & SEM & Mean & SEM & Mean & SEM & Mean & SEM & Mean & SEM \\
\hline Control & $30 \cdot 6$ & $1 \cdot 1$ & $40 \cdot 7$ & 1.0 & $29 \cdot 8$ & $1 \cdot 1$ & $14 \cdot 11$ & 0.24 & $12 \cdot 34$ & $0 \cdot 13$ & 1.77 & 0.29 \\
\hline BTE 50 & 28.4 & 1.8 & $38 \cdot 1$ & 0.8 & 28.6 & 0.8 & $14 \cdot 31$ & 0.07 & $12 \cdot 40$ & $0 \cdot 19$ & 1.91 & $0 \cdot 16$ \\
\hline BTE 100 & $23 \cdot 9^{*}$ & 0.4 & $35 \cdot 6$ & 1.4 & $24 \cdot 3$ & 0.7 & 14.86 & 0.18 & $12 \cdot 80$ & $0 \cdot 19$ & 2.06 & 0.29 \\
\hline GTE 50 & $27 \cdot 9$ & 0.8 & $37 \cdot 8$ & 1.5 & $26 \cdot 7$ & 0.9 & 14.44 & 0.26 & $12 \cdot 43$ & 0.15 & $2 \cdot 01$ & 0.28 \\
\hline GTE 100 & $23 \cdot 5^{\star}$ & 0.6 & $35 \cdot 1$ & 0.7 & $22 \cdot 9^{*}$ & 0.9 & 14.87 & 0.13 & $12 \cdot 87$ & $0 \cdot 11$ & 2.00 & 0.10 \\
\hline Alloxan & $89 \cdot 9^{* *}$ & 0.9 & $148 \cdot 7^{\star *}$ & 1.8 & $99 \cdot 9^{\star \star}$ & 3.0 & $15 \cdot 09^{\star *}$ & 0.21 & $9 \cdot 81^{* *}$ & 0.29 & $5 \cdot 27^{\star \star}$ & 0.28 \\
\hline Alloxan + BTE 50 & $63 \cdot 2^{* \star}+\dagger$ & $2 \cdot 0$ & $82 \cdot 1^{\star \star} \dagger \dagger$ & 1.4 & $52 \cdot 4^{\star *}+\dagger$ & 1.8 & $14.94^{*}$ & 0.15 & $8 \cdot 50^{* *}$ & 0.36 & $6.44^{\star *}$ & 0.44 \\
\hline Alloxan + BTE 100 & $39 \cdot 7^{\star \star}+\dagger$ & 0.4 & $67 \cdot 6^{\star \star}+\dagger$ & $2 \cdot 4$ & $40 \cdot 0^{\star *}+\dagger$ & 0.8 & $14.91^{*}$ & 0.12 & $8.54^{\star *}$ & 0.39 & $6 \cdot 37^{\star *}$ & 0.47 \\
\hline Alloxan + GTE 50 & $61.4^{\star \star}+\dagger$ & 1.9 & $79 \cdot 5^{\star \star}+\dagger$ & 0.9 & $47 \cdot 5^{\star \star}+\dagger$ & 1.0 & $14 \cdot 89$ & 0.11 & $9 \cdot 41^{\star *}$ & 0.59 & $5 \cdot 47^{\star \star}$ & 0.61 \\
\hline Alloxan + GTE 100 & $39 \cdot 0^{\star *}+\dagger$ & $1 \cdot 1$ & $61 \cdot 2^{\star \star}+\dagger$ & $2 \cdot 0$ & $38 \cdot 4^{\star *}+\dagger$ & 0.7 & $14 \cdot 86$ & 0.12 & $9 \cdot 50^{\star \star}$ & 0.24 & $5 \cdot 36^{\star \star}$ & 0.29 \\
\hline Cholesterol & $90 \cdot 8^{\star \star}$ & $2 \cdot 2$ & $129 \cdot 2^{\star \star}$ & $1 \cdot 3$ & $45 \cdot 5^{\star \star}$ & 1.4 & $14 \cdot 97^{\star}$ & 0.18 & $9 \cdot 81^{* *}$ & $0 \cdot 18$ & $5 \cdot 16^{\star \star}$ & 0.21 \\
\hline Cholesterol + BTE 50 & $54 \cdot 8^{\star \star} \neq \ddagger$ & 1.9 & $60 \cdot 3^{\star \star} \ddagger \ddagger$ & $2 \cdot 2$ & $38 \cdot 3^{\star \star} \ddagger$ & 1.6 & $14.96^{*}$ & 0.16 & $9 \cdot 46^{\star *}$ & 0.39 & $5 \cdot 50^{\star \star}$ & 0.37 \\
\hline Cholesterol + BTE 100 & 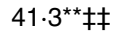 & 1.5 & $48 \cdot 7^{*} \neq \ddagger$ & $1 \cdot 1$ & $36 \cdot 8^{*} \ddagger \ddagger$ & $0 \cdot 8$ & $14.96^{*}$ & 0.10 & $9 \cdot 69^{\star *}$ & 0.22 & $5 \cdot 27^{\star \star}$ & 0.20 \\
\hline Cholesterol + GTE 50 & $46 \cdot 5^{\star \star} \ddagger \ddagger$ & $1 \cdot 2$ & $54 \cdot 2^{\star \star} \neq \ddagger$ & 0.8 & $38 \cdot 0^{\star *} \ddagger \ddagger$ & 1.4 & 14.90 & 0.07 & $9 \cdot 56^{\star *}$ & 0.26 & $5 \cdot 34^{\star \star}$ & 0.23 \\
\hline Cholesterol + GTE 100 & $39 \cdot 7^{\star \star} \ddagger \ddagger$ & $1 \cdot 3$ & $48 \cdot 4^{\star} \ddagger \ddagger$ & $1 \cdot 2$ & $35 \cdot 7 \ddagger \ddagger$ & 1.5 & 14.89 & 0.17 & $9 \cdot 63^{\star \star}$ & 0.35 & $5 \cdot 26^{\star \star}$ & 0.33 \\
\hline
\end{tabular}

ALAT, alanine aminotransferase; ASAT, aspartate aminotransferase; ALP, alkaline phosphatase; BTE 50, black tea aqueous extract (50 mg/kg body weight); BTE 100, black tea aqueous extract (100 mg/kg body weight); GTE 50, green tea aqueous extract (50 mg/kg body weight); GTE 100, green tea aqueous extract (100 mg/kg body weight). Mean value was significantly different from that of the control group: ${ }^{*} P<0.05,{ }^{* \star} P<0.01$.

Mean value was significantly different from that of the alloxan-only-treated group: $\dagger \dagger P<0.01$.

Mean value was significantly different from that of the cholesterol-only-treated group: $\ddagger P<0.05, \ddagger \ddagger P<0.01$. 
ratio $(P<0.01, t=3.788$, difference between means $=0 \cdot 30$, $95 \%$ CI $0.04,0.55)$ and serum direct bilirubin level $(P<0 \cdot 01, t=6 \cdot 027$, difference between means $=0.25,95 \%$ CI $0.12,0.39$ ) compared with the control animals (Tables 1 and 3).

Both tea extracts significantly alleviated $(P<0.05-$ $P<0.01)$ the increase in body weight and liver weight:body weight ratio (Table 1), serum glucose, total lipid, TAG and phospholipid levels (Tables 1 and 2), atherogenic index values (Table 2), and serum aminotransferase and ALP activities (Table 3) induced by the cholesterol-rich diet. These modulatory effects of tea extracts were dose dependent and slightly more in the GTE groups compared with the BTE groups in most cases. Body-weight gain, serum total lipid and TAG levels, and serum ALP activity became comparable with those of the control group $(P>0.05)$ in the group that received the cholesterol-rich diet plus the high dose of GTE only. There were no significant modulatory effects of both tea extracts on A:G ratio and serum bilirubin (total, direct and indirect) level in groups that received the cholesterol-rich diet plus tea extracts compared with the group that received the cholesterol-rich diet only. Food intake was not significantly altered $(P>0.05)$ in cholesterol-rich diet with or without tea extracts-treated groups compared with the control group (Fig. 1).

The percentages of changes of all parameters measured in the group that received the cholesterol-rich diet only, groups that received the cholesterol-rich diet plus either the low or high dose of BTE, and groups that received the cholesterolrich diet plus either the low or high dose of GTE were 170.9 (SEM 94.4), 83.9 (SEM 43.7), 50.9 (SEM 27.9), 78.0 (SEM 45.2) and 44.9 (SEM 26.1), respectively, compared with the control group. All of these data indicated that the most modulatory effects on obese rats were induced by the high dose of BTE and GTE.

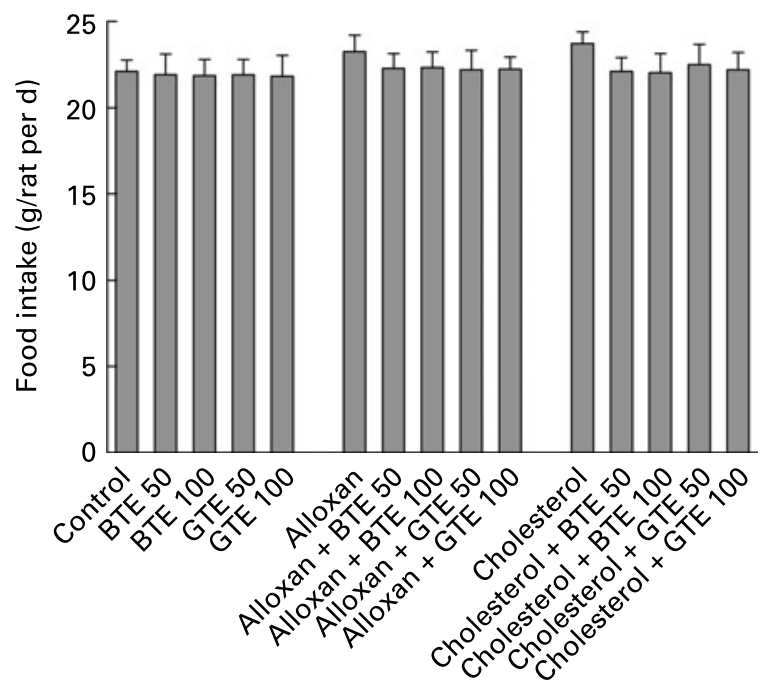

Fig. 1. Food intake ( $g /$ rat per $d$ ) in healthy, diabetic, and obese rat models treated with or without tea extracts. BTE 50 , black tea aqueous extract (50 mg/kg body weight); BTE 100 , black tea aqueous extract $(100 \mathrm{mg} / \mathrm{kg}$ body weight); GTE 50 , green tea aqueous extract $(50 \mathrm{mg} / \mathrm{kg}$ body weight); GTE 100 , green tea aqueous extract $(100 \mathrm{mg} / \mathrm{kg}$ body weight). Values are means, with standard errors represented by vertical bars.
Beneficial and deleterious effects caused by black tea aqueous extract and green tea aqueous extract consumption in healthy rats

The present study showed that treatment of rats with tea extracts alone did not significantly affect $(P>0 \cdot 05)$ the liver weight:body weight and $A: G$ ratios, clotting time, serum total protein, phospholipid and bilirubin (total, direct and indirect) levels, atherogenic index values, and serum aspartate aminotransferase activity compared with the control animals (Tables 1-3). Food intake was not significantly affected $(P>0.05)$ in the tea extracts-treated groups compared with the control group (Fig. 1). Also, tea consumption did not significantly alter $(P>0.05)$ the globulin fractions $\left(\alpha_{1}, \alpha_{2}, \beta\right.$ and $\gamma$ globulins), kidney functions (serum urea and creatinine levels), erythrocyte and platelet counts, $\mathrm{Hb}$ content, packed cell volume value and blood indices in healthy rats (data not shown). On the other hand, rats treated with the high dose of either BTE or GTE showed a significant decrease $(P<0 \cdot 05-P<0 \cdot 01)$ in serum glucose, total lipid and TAG levels (Tables 1 and 2), and alanine aminotransferase activity (Table 3 ) compared with the control animals. In addition, only rats treated with the high dose of GTE showed a significant decrease in body-weight gain $(P<0.01, t=3.998$, difference between means $=10.86,95 \%$ CI $1.95,19.77)$ and serum ALP activity $(P<0.05, \quad t=3.594$, difference between means $=6 \cdot 94,95 \%$ CI $0 \cdot 60,13 \cdot 27)$ compared with the control animals. All of these observations indicated that the most beneficial effects on healthy rats were induced by the high dose of BTE and GTE.

The only deleterious effects of tea consumption detected in the present study were the significant reduction in spleen weight:body weight ratio $(P<0.05)$ and the induction of leucopenia $(P<0 \cdot 01)$, which is mainly due to lymphopenia $(P<0.01)$, in rats that received the high dose of either BTE or GTE only compared with the control animals (Figs. 2 and 3).

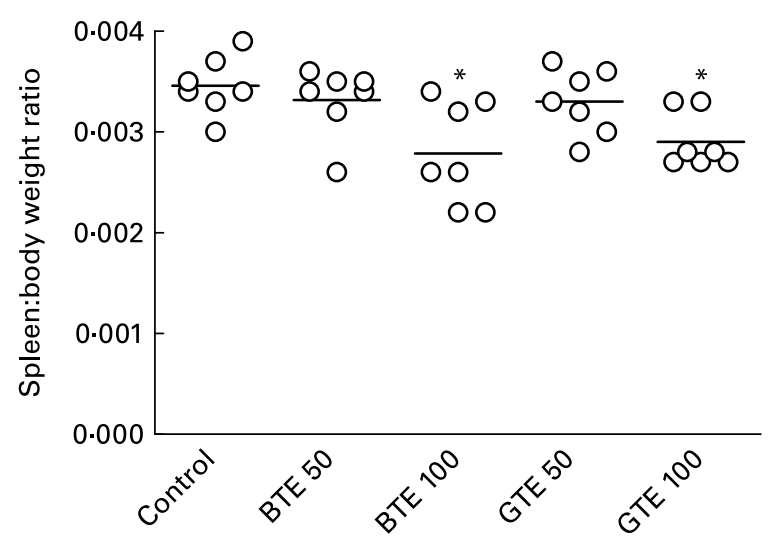

Fig. 2. Spleen weight:body weight ratio in control and tea-only-treated animals. BTE 50 , black tea aqueous extract $(50 \mathrm{mg} / \mathrm{kg}$ body weight); BTE 100 , black tea aqueous extract (100 mg/kg body weight); GTE 50, green tea aqueous extract $(50 \mathrm{mg} / \mathrm{kg}$ body weight); GTE 100 , green tea aqueous extract $(100 \mathrm{mg} / \mathrm{kg}$ body weight). Individual values are shown, with means represented by horizontal bars. * Mean value was significantly different from that of the control group $(P<0.05)$. 

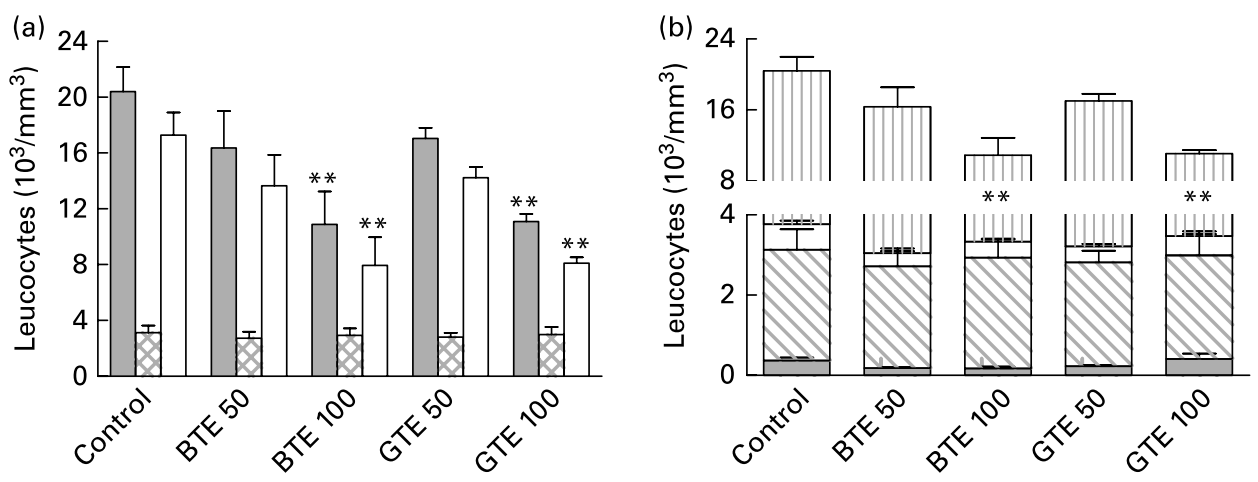

Fig. 3. (a) Total leucocyte counts in control and tea-only-treated animals. ( $\square$ ), Total leucocytes; (XX), total granulocytes; ( $\square$ ), total agranulocytes. (b) Differential

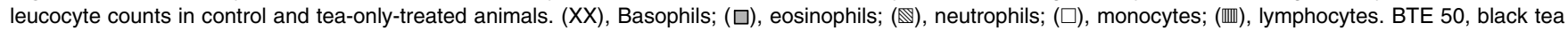
aqueous extract $(50 \mathrm{mg} / \mathrm{kg}$ body weight); BTE 100 , black tea aqueous extract $(100 \mathrm{mg} / \mathrm{kg}$ body weight); GTE 50 , green tea aqueous extract (50 mg/kg body weight); GTE 100, green tea aqueous extract (100 mg/kg body weight). Values are means, with standard errors represented by vertical bars. ${ }^{\star \star}$ Mean value was significantly different from that of the control group $(P<0.01)$

\section{Discussion}

Alloxan produces oxygen radicals, which destroy pancreatic $\beta$-cells and cause severe hypoinsulinaemia (type 1 diabetes) that is responsible for the hyperglycaemia and dyslipidaemia seen in alloxan-treated animals ${ }^{(17,36)}$. However, its action is not directed to pancreatic $\beta$-cells only, as other organs such as the liver, kidney and bone marrow are also affected by alloxan administration as seen from the elevation of plasma markers reflecting hepatic and renal cell damage (alanine aminotransferase activity, total:direct bilirubin ratio, and urea and creatinine levels) and the reduction of haematological parameters $^{(17)}$. Weight loss (one of the clinical features of type 1 diabetes) seen in alloxan-treated animals may be due to the degeneration of the adipocytes and muscle tissues to compensate for the energy lost from the body due to frequent urination and over-conversion of glycogen to glucose ${ }^{(37)}$. On the other hand, there is a strong positive correlation between a high-cholesterol diet and increased production of reactive oxygen species and decreased activities of endogenous radical scavengers that lead to increased incidence of the metabolic syndrome, a clustering of pathological conditions including obesity, dyslipidaemia, hepatic steatosis and insulin resistance

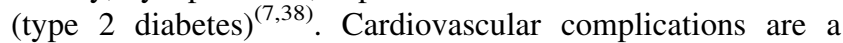
major cause of morbidity and mortality in patients with diabetes, obesity and the metabolic syndrome ${ }^{(39-41)}$.

The present study showed that both tea extracts significantly alleviated most signs of the metabolic syndrome including hyperglycaemia (resulting from type 1 and 2 diabetes), hyperlipidaemia and impairment of liver functions induced by alloxan or a cholesterol-rich diet in male albino rats. The hypolipidaemic effect and the marked decrease in atherogenic indexes shown in the present study by tea extracts in alloxan or high-cholesterol diet-treated rats (Table 2) may reduce the incidence of atherosclerosis in diabetic and obese patients. The most interesting finding in the present study was that tea extracts significantly modulated both the severe decrease and increase in body weight induced by alloxan and the high-cholesterol diet, respectively (Table 1). Maintenance of a constant body weight requires a balance between cellular energy intake and energy expenditure. A slight imbalance in this energy equilibrium can lead to significant changes in body weight and may eventually result in obesity or slimness ${ }^{(6)}$. In the present study, neither daily nor total food intake was significantly changed during the treatment period among all groups (Fig. 1). The significant increase in bodyweight gain induced by tea extracts in the diabetic rats, despite similar food consumption, suggests that BTE and GTE may have a positive anabolic effect by decreasing the degeneration of the adipocytes and muscle tissues through improving glucose metabolism. On the other hand, the significant decrease in body-weight gain and liver weight:body weight ratio induced by both BTE and GTE in the obese rats may be due to a reduction in body and liver fats by improving lipid metabolism, increasing energy expenditure, and affecting fat absorption and excretion. Thus, the results of the present study suggest a direct effect of tea extracts on the improvement of metabolism rather than affecting food intake.

Several other studies reported that the hypoglycaemic effect of tea was attributed to the presence of polyphenols, catechins and a water-soluble polysaccharide fraction ${ }^{(17,42-45)}$. Also, it was found that tea consumption significantly decreased blood glucose levels by increasing hepatic glycogen level in alloxan-diabetic rats possibly through reactivation of the glycogen synthase system (as a result of increased insulin secretion) and decreasing liver glucose-6-phosphatase activity, which is mainly responsible for releasing glucose molecules to the blood by converting glucose-6-phosphate to glu$\operatorname{cose}^{(17,36,46)}$. Moreover, Anandh Babu et al. ${ }^{(8)}$ reported that the increase in insulin-stimulated glucose uptake, inhibition of the intestinal GLUT system and decrease in expression of genes that control gluconeogenesis are the mechanisms proposed to be responsible for the anti-hyperglycaemic effect of tea.

BTE has been found to quench reactive oxygen species such as singlet oxygen, superoxide and hydroxyl radicals ${ }^{(18)}$, which may explain its hypoglycaemic activity obtained in the present study. Other studies reported that green tea epigallocatechin gallate promotes pancreatic $\beta$-cell regeneration in alloxan-treated rats, has insulin-like and insulinotropic activities, and inhibits gluconeogenesis through inhibition of liver phosphoenolpyruvate kinase synthesis ${ }^{(3,46,47)}$. The study of Wolfram et al. ${ }^{(48)}$ also demonstrated that green tea epigallocatechin gallate possesses pronounced anti-diabetic efficacy in preclinical 
models of type 2 diabetes mellitus, which is at least partially mediated through reducing the hepatic glucose production and enhancing the pancreatic function.

Based on biochemical and pharmacological studies, the mechanisms of preventing obesity by tea consumption may be through stimulating hepatic lipid metabolism, inhibiting gastric and pancreatic lipases, stimulating thermogenesis and suppressing fatty acid synthase by black tea theaflavins and green tea catechins ${ }^{(4,6)}$. Both black and green tea leaves have been found to decrease plasma TAG, cholesterol and LDL-cholesterol in rats by decreasing lipogenesis ${ }^{(49)}$. In addition, black and green tea polyphenols were found to modulate the hypercholesterolaemia in the experimental animals by up-regulating the liver LDL receptor, inhibiting cholesterol synthesis, and increasing faecal excretion of cholesterol, total fatty acids and bile acid ${ }^{(50-52)}$.

BTE supplementation has the ability to restore the activity of antioxidant enzymes, reduce the generation of free radicals, blunt lipid peroxidation and prevent hepatocellular damage in rats receiving ethanol with or without a high-fat diet ${ }^{(18)}$. Moreover, black tea theaflavins has the ability to reduce hepatic lipid accumulation both in vitro and in vivo ${ }^{(53)}$. The release of liver alanine aminotransferase, aspartate aminotransferase and ALP was inhibited in rats probably by chemical components of black tea that may stabilise the integrity of the cell membrane and keeping the membrane intact and the enzymes enclosed through scavenging free radicals ${ }^{(54)}$. Thus, the hepatoprotective effect of BTE found in the present study may be due to inhibition of the oxidative stress, induced by alloxan and the cholesterol-rich diet, by increasing cellular antioxidant capacity and reducing membrane lipid peroxidation. On the other hand, it has been found that green tea epigallocatechin gallate inhibited obesity, the metabolic syndrome, hepatic steatosis and the release of liver enzymes induced by a high-fat diet in mice ${ }^{(7)}$. Other studies reported that green tea epigallocatechin gallate inhibited lipid absorption through its ability to form complexes with lipids and lipolytic enzymes and hence interfering with the luminal processes of emulsification, hydrolysis, micellar solubilisation, and subsequent uptake of lipids ${ }^{(55,56)}$. Green tea epicatechins and epigallocatechin gallate have been found to modulate the increase in LDL-cholesterol, probably by decreasing the apoB (the principal protein that comprises nearly $90 \%$ of total protein mass of LDL), and the decrease in HDL-cholesterol in experimental animals fed a high-fat or high-cholesterol diet ${ }^{(57,58)}$.

Flavonols are less affected by tea processing and are present in comparable amounts in both green and black teas ${ }^{(59,60)}$. Theaflavins present in black tea possess the same antioxidant potency as catechins present in green tea, and the conversion of catechins to theaflavins during fermentation in making black tea does not alter significantly their free radical-scavenging activity ${ }^{(61)}$. In the past few years, it has been reported that AMP-activated protein kinase (AMPK) plays a key role in regulating carbohydrate and fat metabolism, serving as a metabolic master switch in response to alterations in cellular energy charge ${ }^{(53)}$. AMPK is physiologically activated by the phosphorylation of threonine 172 within the $\alpha$-subunit catalysed by the kinase LKB1, the upstream kinase of $\mathrm{AMPK}^{(62)}$. AMPK activation results in the phosphorylation and inhibition of acetyl-CoA carboxylase, in addition to the loss of inhibition of carnitine palmitoyl transferase I by decreasing the concentration of malonyl-CoA, leading to increased fatty acid oxidation. AMPK also regulates glucose homeostasis by modulating gluconeogenesis-related molecules, such as phosphoenolpyruvate carboxykinase and glucose-6-phosphatase in the liver. In addition, AMPK activation inhibits adipocyte differentiation and suppresses the expression of lipogenic molecules, such as fatty acid synthase, acetyl-CoA carboxylase and PPAR- $\gamma^{(63)}$. Therefore, based on the central role of AMPK in the regulation of energy metabolism, it may be a promising molecular target for the suppression of obesity and the treatment of the metabolic syndrome. Recently, it was found that both black tea theaflavins and green tea catechins significantly attenuated the high glucose-induced insulin signalling blockade, reduced lipid accumulation, suppressed fatty acid synthesis, and stimulated fatty acid oxidation through activating the LKB1-AMPK pathway in cultured cells and BALB/c mice ${ }^{(53,63,64)}$. All of these findings may rationalise the striking similarity in the functional effects of BTE and GTE obtained in the present study, despite the considerable difference in the chemical composition of both tea extracts.

All modulatory effects obtained in the present study were increased by increasing the dose of tea extracts. The modulatory effects of the highest dose of GTE were slightly more in most cases in the present study. In addition, only the high dose of GTE modulated completely hypertriacylglycerolaemia induced by alloxan and the cholesterol-rich diet. Also, the significant elevations in body weight, serum total lipid level, and serum ALP activity induced by the cholesterol-rich diet were completely modulated by the high dose of GTE only. Although the difference in effect size between the highest dose of GTE and BTE was very subtle for each parameter measured here, the modulatory effects for all parameters together in the obese and diabetic rats were from 6.0 (SEM 2.6 ) to 10.9 (SEM 6.3) \% higher in the groups that received the high dose of GTE than in those that received the high dose of BTE. This may be because green tea contains more antioxidant compounds compared with black tea as reported by Steele et al. ${ }^{(65)}$.

No modulatory effects were detected for both tea extracts on $A: G$ ratio and serum bilirubin levels in both animal models used in the present study. This may be due to the doses used here, which can be considered low. Another interesting finding of the present study was that no harmful effects were detected for tea consumption on all parameters measured, except that the high dose of both tea extracts significantly decreased spleen weight:body weight ratio (Fig. 2), probably due to decreasing its cellularity, and induced lymphopenia (Fig. 3). This may be beneficial in alleviating the undesirable hyperimmune response found in autoimmune diseases such as rheumatoid arthritis. This topic needs further investigation and will be considered in the future.

In general, the modulatory effects of BTE and GTE on some parameters measured in the present study were partial, but significant, and dose dependent. Therefore, it may be more beneficial if the dose increased in future studies. The present study supports the hypothesis that both black and green teas may have beneficial effects against the risks of the metabolic syndrome and CVD as shown in rat models of human obesity and diabetes. 


\section{Acknowledgements}

This research received no specific grant from any funding agency in the public, commercial or not-for-profit sectors.

N. M. E.-B. and G. R. planned the study, designed all experiments, summarised, discussed and interpreted the results, and drafted the manuscript. E. A. A. E.-G. carried out the experiments and performed the statistical analysis with assistance from $\mathrm{G}$. R.

The authors have no potential financial conflict of interest.

\section{References}

1. Lefebvre P (2005) Diabetes yesterday, today and tomorrow. The action of the International Diabetes Federation. Rev Med Liege 60, 273-277.

2. Crespy V \& Williamson G (2004) A review of the health effects of green tea catechins in in vivo animal models. J Nutr 134, 3431S-3440S.

3. Islam MS \& Choi H (2007) Green tea, anti-diabetic or diabetogenic: a dose response study. Biofactors 29, 45-53.

4. Murase T, Nagasawa A, Suzuki J, et al. (2002) Beneficial effects of tea catechins on diet-induced obesity: stimulation of lipid catabolism in the liver. Int $J$ Obes Relat Metab Disord 26, 1459-1464.

5. Rossner S (2002) Obesity: the disease of the twenty-first century. Int J Obes Relat Metab Disord 26, Suppl. 4, S2-S4.

6. Lin JK \& Lin-Shiau SY (2006) Mechanisms of hypolipidemic and anti-obesity effects of tea and tea polyphenols. Mol Nutr Food Res 50, 211-217.

7. Bose M, Lambert JD, Ju J, et al. (2008) The major green tea polyphenol, (-)-epigallocatechin-3-gallate, inhibits obesity, metabolic syndrome, and fatty liver disease in high-fat-fed mice. J Nutr 138, 1677-1683.

8. Anandh Babu PV, Sabitha KE \& Shyamaladevi CS (2006) Green tea extract impedes dyslipidaemia and development of cardiac dysfunction in streptozotocin-diabetic rats. Clin Exp Pharmacol Physiol 33, 1184-1189.

9. Klaus S, Pultz S, Thone-Reineke C, et al. (2005) Epigallocatechin gallate attenuates diet-induced obesity in mice by decreasing energy absorption and increasing fat oxidation. Int $J$ Obes (Lond) 29, 615-623.

10. McKay DL \& Blumberg JB (2007) Roles for epigallocatechin gallate in cardiovascular disease and obesity: an introduction. J Am Coll Nutr 26, 362S-365S.

11. Yokozawa T, Nakagawa T \& Kitani K (2002) Antioxidative activity of green tea polyphenol in cholesterol-fed rats. $J$ Agric Food Chem 50, 3549-3552.

12. Chen H, Zhang M \& Xie B (2005) Components and antioxidant activity of polysaccharide conjugate from green tea. Food Chem 90, 17-21.

13. Cabrera C, Artacho R \& Gimenez R (2006) Beneficial effects of green tea - a review. J Am Coll Nutr 25, 79-99.

14. Wolfram S (2007) Effects of green tea and EGCG on cardiovascular and metabolic health. J Am Coll Nutr 26, 373S-388S.

15. Harbowy ME \& Balentine DA (1997) Tea chemistry. Crit Rev Plant Sci 16, 415-448.

16. Riemersma RA, Rice-Evans CA, Tyrrell RM, et al. (2001) Tea flavonoids and cardiovascular health. QJM 94, 277-282.

17. Sabu MC, Smitha K \& Kuttan R (2002) Anti-diabetic activity of green tea polyphenols and their role in reducing oxidative stress in experimental diabetes. J Ethnopharmacol 83, 109-116.

18. Das D, Mukherjee S, Mukherjee M, et al. (2005) Aqueous extract of black tea (Camellia sinensis) prevents chronic ethanol toxicity. Curr Sci 88, 952-961.
19. Cooperstien SJ \& Walkins D (1981) Action of toxic drugs on islet cells. In The Islets of Langerhans, pp. 387-390 [SJ Cooperstein and D Watkins, editors]. New York: Academic Press.

20. Csont T, Balogh G, Csonka C, et al. (2002) Hyperlipidemia induced by high cholesterol diet inhibits heat shock response in rat hearts. Biochem Biophys Res Commun 290, $1535-1538$.

21. Onody A, Csonka C, Giricz Z, et al. (2003) Hyperlipidemia induced by a cholesterol-rich diet leads to enhanced peroxynitrite formation in rat hearts. Cardiovasc Res 58, 663-670.

22. Trinder P (1969) Determination of glucose in blood using glucose oxidase with an alternative oxygen acceptor. Ann Clin Biochem 6, 24-27.

23. Frings CS \& Dunn RT (1970) A colorimetric method for determination of total serum lipids based on the sulfophospho-vanillin reaction. Am J Clin Pathol 53, 89-91.

24. Doumas BT, Watson WA \& Biggs HG (1971) Albumin standards and the measurement of serum albumin with bromcresol green. Clin Chim Acta 31, 87-96.

25. Allain CC, Poon LS, Chan CS, et al. (1974) Enzymatic determination of total serum cholesterol. Clin Chem 20, 470-475.

26. Vikari J (1976) Precipitation of plasma lipoproteins by PEG-6000 and its evaluation with electrophoresis and ultracentrifugation. Scand J Clin Lab Invest 36, 265-268.

27. Takayama M, Itoh S, Nagasaki T, et al. (1977) A new enzymatic method for determination of serum choline-containing phospholipids. Clin Chim Acta 79, 93-98.

28. Doumas BT, Bayse DD, Carter RJ, et al. (1981) A candidate reference method for determination of total protein in serum. I. Development and validation. Clin Chem 27, 1642-1650.

29. McGowan MW, Artiss JD, Strandbergh DR, et al. (1983) A peroxidase-coupled method for the colorimetric determination of serum triglycerides. Clin Chem 29, 538-542.

30. Trinder P \& Webster D (1984) Determination of HDL-cholesterol using 2,4,6-tribromo-3-hydroxybenzoic acid with a commercial CHOD-PAP reagent. Ann Clin Biochem 21, 430-433.

31. Fossati P, Ponti M, Prencipe L, et al. (1989) One-step protocol for assays of total and direct bilirubin with stable combined reagents. Clin Chem 35, 173-176.

32. Reitman S \& Frankel S (1957) A colorimetric method for the determination of serum glutamic oxalacetic and glutamic pyruvic transaminases. Am J Clin Pathol 28, 56-63.

33. Tietz NW, Burtis CA, Duncan P, et al. (1983) A reference method for measurement of alkaline phosphatase activity in human serum. Clin Chem 29, 751-761.

34. Friedewald WT, Levy RI \& Fredrickson DS (1972) Estimation of the concentration of low-density lipoprotein cholesterol in plasma, without use of the preparative ultracentrifuge. Clin Chem 18, 499-502.

35. Turner JR \& Thayer JF (editors) (2001) Introduction to Analysis of Variance: Design, Analysis and Interpretation. Thousand Oaks, CA: Sage Publications.

36. Moram GS (2001) Effect of aqueous extracts from some plants on alloxan - diabetic rats. Egypt J Hosp Med 2, 57-69.

37. Ene AC, Nwankwo EA \& Samdi LM (2007) Alloxan-induced diabetes in rats and the effects of black caraway (Carum carvi L.) oil on their body weight. Res J Med Med Sci 2, 48-52.

38. Czako L, Szabolcs A, Vajda A, et al. (2007) Hyperlipidemia induced by a cholesterol-rich diet aggravates necrotizing pancreatitis in rats. Eur J Pharmacol 572, 74-81.

39. Butler J, Rodondi N, Zhu Y, et al. (2006) Metabolic syndrome and the risk of cardiovascular disease in older adults. $J \mathrm{Am}$ Coll Cardiol 47, 1595-1602.

40. Knuiman MW, Hung J, Divitini ML, et al. (2009) Utility of the metabolic syndrome and its components in the prediction of incident cardiovascular disease: a prospective cohort study. Eur J Cardiovasc Prev Rehabil 16, Suppl. 2, 235-241. 
41. Thorn LM, Forsblom C, Waden J, et al. (2009) Metabolic syndrome as a risk factor for cardiovascular disease, mortality, and progression of diabetic nephropathy in type 1 diabetes. Diabetes Care 32, Suppl. 5, 950-952.

42. Shimizu M, Kobayashi Y, Suzuki M, et al. (2000) Regulation of intestinal glucose transport by tea catechins. Biofactors 13, $61-65$.

43. Kim MJ, Ryu GR, Chung JS, et al. (2003) Protective effects of epicatechin against the toxic effects of streptozotocin on rat pancreatic islets: in vivo and in vitro. Pancreas 26, 292-299.

44. Janle EM, Portocarrero C, Zhu Y, et al. (2005) Effect of longterm oral administration of green tea extract on weight gain and glucose tolerance in Zucker diabetic (ZDF) rats. J Herb Pharmacother 5, 55-65.

45. Zhou X, Wang D, Sun P, et al. (2007) Effects of soluble tea polysaccharides on hyperglycemia in alloxan-diabetic mice. J Agric Food Chem 55, 5523-5528.

46. Waltner-Law ME, Wang XL, Law BK, et al. (2002) Epigallocatechin gallate, a constituent of green tea, represses hepatic glucose production. J Biol Chem 277, 34933-34940.

47. Chemler JA, Lock LT, Koffas MA, et al. (2007) Standardized biosynthesis of flavan-3-ols with effects on pancreatic $\beta$-cell insulin secretion. Appl Microbiol Biotechnol 77, 797-807.

48. Wolfram S, Raederstorff D, Preller M, et al. (2006) Epigallocatechin gallate supplementation alleviates diabetes in rodents. J Nutr 136, 2512-2518.

49. Kuo KL, Weng MS, Chiang CT, et al. (2005) Comparative studies on the hypolipidemic and growth suppressive effects of oolong, black, pu-erh, and green tea leaves in rats. J Agric Food Chem 53, 480-489.

50. Matsumoto N, Okushio K \& Hara Y (1998) Effect of black tea polyphenols on plasma lipids in cholesterol-fed rats. J Nutr Sci Vitaminol (Tokyo) 44, Suppl. 2, 337-342.

51. Yang TT \& Koo MW (2000) Chinese green tea lowers cholesterol level through an increase in fecal lipid excretion. Life Sci 66, 411-423.

52. Bursill CA, Abbey M \& Roach PD (2007) A green tea extract lowers plasma cholesterol by inhibiting cholesterol synthesis and upregulating the LDL receptor in the cholesterol-fed rabbit. Atherosclerosis 193, 86-93.
53. Lin CL, Huang HC \& Lin JK (2007) Theaflavins attenuate hepatic lipid accumulation through activating AMPK in human HepG2 cells. J Lipid Res 48, 2334-2343.

54. Oyejide OO \& Olushola L (2005) Hepatoprotective and antioxidant properties of extract of Carmellia sinensis (black tea) in rats. Afr J Biotechnol 4, 1432-1438.

55. Raederstorff DG, Schlachter MF, Elste V, et al. (2003) Effect of EGCG on lipid absorption and plasma lipid levels in rats. $J$ Nutr Biochem 14, 326-332.

56. Koo SI \& Noh SK (2007) Green tea as inhibitor of the intestinal absorption of lipids: potential mechanism for its lipid-lowering effect. J Nutr Biochem 18, 179-183.

57. Chan PT, Fong WP, Cheung YL, et al. (1999) Jasmine green tea epicatechins are hypolipidemic in hamsters (Mesocricetus auratus) fed a high fat diet. J Nutr 129, 1094-1101.

58. Yee WL, Wang Q, Agdinaoay T, et al. (2002) Green tea catechins decrease apolipoprotein B-100 secretion from HepG2 cells. Mol Cell Biochem 229, 85-92.

59. Balentine DA, Wiseman SA \& Bouwens LC (1997) The chemistry of tea flavonoids. Crit Rev Food Sci Nutr 37, 693-704.

60. Keith RP, Michael JCR \& Karen AB (1998) Flavonol glycoside content and composition of tea infusions made from commercially available teas and tea products. J Agric Food Chem 46, Suppl. 7, 2517-2522.

61. Leung LK, Su Y, Chen R, et al. (2001) Theaflavins in black tea and catechins in green tea are equally effective antioxidants. J Nutr 131, 2248-2251.

62. Taylor EB, Ellingson WJ, Lamb JD, et al. (2005) Long-chain acyl-CoA esters inhibit phosphorylation of AMP-activated protein kinase at threonine-172 by LKB1/STRAD/MO25. Am $J$ Physiol Endocrinol Metab 288, E1055-E1061.

63. Murase T, Misawa K, Haramizu S, et al. (2009) Catechininduced activation of the LKB1/AMP-activated protein kinase pathway. Biochem Pharmacol 78, 78-84.

64. Lin CL \& Lin JK (2008) Epigallocatechin gallate (EGCG) attenuates high glucose-induced insulin signaling blockade in human hepG2 hepatoma cells. Mol Nutr Food Res 52, 930-939.

65. Steele VE, Kelloff GJ, Balentine D, et al. (2000) Comparative chemopreventive mechanisms of green tea, black tea and selected polyphenol extracts measured by in vitro bioassays. Carcinogenesis 21, 63-67. 